\title{
An Analysis of Interest Imbalance of Farmers in Basic Farmland Protection Areas
}

\author{
Haida Zhang ${ }^{1} \&$ Jianqiang $\mathrm{Li}^{1}$ \\ ${ }^{1}$ College of Economics and Management, Sichuan Agricultural University, Chengdu, China \\ Correspondence: Haida Zhang, College of Economics and Management, Sichuan Agricultural University, \\ Chengdu 611130, Sichuan, China. E-mail: zhanghaida1003@163.com
}

Received: May 4, 2012 Accepted: June 15, 2012 Online Published: August 17, 2012

doi:10.5539/ass.v8n11p44

URL: http://dx.doi.org/10.5539/ass.v8n11p44

\begin{abstract}
Ever since China carried out the policy of basic farmland protection, the speed of reduction in the amount of cultivated land resources has been alleviated to a certain extent, which indicates that the policy of basic farmland protection has achieved certain effect. However, with elapsing of the time, negative effects of the protection policy also begins to emerge. Taking the data about a field survey in Wuhan as the case study, this article makes a comparison between the income pattern and level of farmers both from basic farmland protection areas and from non-basic farmland protection areas, works out the opportunity cost of farmers' protection of cultivated land in the protection areas, employs the cost benefit analysis method and gets the following specific conclusions. In terms of planting structure, what farmers from protection areas plant most is food crop, whereas farmers from non-protection areas mostly plant commercial crop. This difference of planting structure leads to imbalance of interests of farmers. In terms of the income level, the proportion of income of farmers in protection areas to the income of farmers in non-protection areas is 1:4.3. Meanwhile, the proportion of income of farmers in protection areas to the income of urban residents is 1:6.25, indicating an extremely obvious interest imbalance.
\end{abstract}

Keywords: opportunity cost, interest imbalance, basic farmland, protection area

\section{Problems Proposed}

It was pointed out in the Third Plenary Session of the Seventeenth Central Committee of the Communist Party of China, we had to adhere to the most strict cultivated land protection system, put responsibilities into action at different levels and stick to the 1.8 billion $\mathrm{Mu}$ red line of cultivated land. With the social development of China and expedited speed of urbanization, the area of cultivated land has been reduced largely, which has begun to threaten the food security of the country. In order to respond to this crisis, the government has promulgated corresponding land protection policies to seek for rational development and use of land resources. It is under such a background that the basic farmland protection policy was put forward.

However, as the top priority of protection of cultivated land, basic farmland protection work has not been effectively and the reason is that the enthusiasm of the subjects of basic farmland protection has not been effectively stimulated. The method of the government for basic farmland protection is still mainly to depend on mandatory policies to guarantee implementation of the basic farmland protection, as a result of which the interests of farmers in the protection areas have not deserved due emphasis. With the change of the economic development mode, as the subjects of basic farmland protection, farmers will necessarily choose the subsistence mode of maximization of benefit. Compared with farmers in non-basic farmland protection areas, farmers in basic farmland protection areas have a continuously reduced index of living standard, which leads to difference between the policy will and farmers' will in the process of basic farmland protection. Under such circumstance, this article makes a research and analysis of the interest imbalance condition in the basic farmland protection areas.

\section{An Analysis of Survey Data}

The government carried out a series of quite strict cultivated land protection policies, including such external institutional systems as "Land Administration Law of the People's Republic of China" and "Regulations on the Protection of Basic Farmland" as the backbone and such internal operation specifications as "Technical rules for 
the delimitation of basic farmland protection zones" and "Technical rules for the environment of basic farmland protection Zones" as the backbone. Nevertheless, in the actual implementation process, the job of basic farmland protection is not up to expectations. The fundamental reason is that the enthusiasm of the subjects of basic farmland protection has not been fully exerted. As the subjects of protection, farmers have no initiative right of selection in this process, but can only perform their responsibility under mandatory stipulation of the policies. Meanwhile, what this process has brought to farmers in the protection areas is not actual profit, but relative loss.

In order to have a more intuitive and actual understanding in this issue, the author, together with other researchers, designs a questionnaire and makes a field survey and collects data in the downtown of Wuhan and the surrounding areas so as to explain the issue with the fact.

\subsection{Distribution of Questionnaire}

In this survey, altogether 455 questionnaires were sent out, including 205 questionnaires sent out to farmers and 250 questionnaires sent out to residents in cities. Among the 205 questionnaires sent out to farmers, 189 effective questionnaires were taken back, which included 168 questionnaires in the protection areas and 21 questionnaires in the non-protection areas. And among the 250 questionnaires sent out the residents in cities, 238 effective questionnaires were taken back and the rate of recovery achieved more than $90 \%$.

The objects in the field survey included residents in the six major districts of Wuchang, Hongshan, Qingshan, Hankou, Jiang'an and Hanyang and farmers in the villages of Minzhu Village and Qunjian Village in Wulongquan Town and Shengli Village in Zhifang Town of Jiangxia District in Wuhan City, Dashan Village and Cheling Village in Yuxian Town and Hongqi Village and Laoshichen Village in Zhashan Town of Caidian District, Liuhexin Village in Xingou Town and Wolong Village and Caochang Village in Hebaohu Town of Dongxihu District. The focus of this survey was the pattern of questionnaire survey and different questionnaire surveys were designed respectively for residents and farmers, which was assisted by interview and discussion.

The survey on residents spread over the six major districts in three towns of Wuhan City and the survey scope was extensive and comprehensive. However, the survey on farmers mainly chose farmers in the urban and rural combination areas of Jiangxi District, Caidian District, Dongxihu District and Hongshan District with the method of questionnaire survey and interview. The evidence for selection and determination of the areas for survey on farmers is that, the above four areas are respectively typical rural area within the basic farmland protection area, rural area in urban exurb, rural area in urban outskirts and non-basic farmland protection area. This sort of area selection helps to make a horizontal comparative analysis of the agricultural income of peasant households in different areas and quantization of their interest imbalance.

\subsection{An Analysis of the Structure of Interviewees}

\subsubsection{An Analysis of the Gender Proportion}

Among the 238 effective questionnaires for residents that were taken back, the gender of male interviewees and the gender of female interviewees respectively accounted for a proportion of $60 \%$ (142 questionnaires) and $40 \%$ (96 questionnaires). Among the 189 effective questionnaires for farmers that were taken back, the gender of male interviewees and female interviewees respectively accounted for 58\% (109 questionnaires) and 42\% (80 questionnaires). Thus, it can be seen that, moderateness of the proportion of gender was guaranteed for these two survey groups and effectiveness of the questionnaire survey data was also guaranteed.

\subsubsection{An Analysis of the Age Structure}

In the survey, the urban residents at the age between 18 and 25 were mostly surveyed. Since this group of interviewees has relatively strong capacity in accepting all aspects of things, authenticity of the data about the survey objects is relatively reliable. In the questionnaire survey of farmers, most objects are farmers at the age of 40 or so. Since this group of objects is the subject in the rural labor force, they have profound experience and understanding in the survey content. Therefore, generally speaking, the age structure of the survey is relatively rational.

\subsubsection{An Analysis of the Cultural Background}

In the survey, the general cultural backgrounds of farmers and urban citizens have quite obvious discrepancy. The cultural level of urban citizens is concentrated on technical secondary school, junior college and undergraduate university, whereas the cultural level of farmers is concentrated on illiteracy, primary school and junior high school. This, to some extent, brings certain difficulty to our field survey in rural areas. Thus, with regards to the questionnaire survey on farmers, we partly adopted the method of informal discussion to collect data, which similarly ensured the authenticity and effectiveness of the data. 


\section{An Analysis of the Interest Imbalance of Farmers}

\subsection{Imbalance of Interests Reflected by the Planting Structure}

\subsubsection{The Planting Structure of Farmers in the Protection Areas}

Ever since the cultivated land is delimitated as the basic farmland protection area, the structure of crops planted by farmers is constrained and they have no other choice but to plant food crops. However, cultivation of food crops has large input and relatively small profit, so farmers have to take other measures to increase their sources of income in order to make a living. For example, they may choose to plant commercial crops in the basic farmland or leave the farmland uncultivated and go outside to cities to seek a job, which causes both quality and quantity of the basic farmland to reduce.

Comparing the planting structure of food crops and commercial crops in different types of rural areas in the basic farmland protection areas, we find that, the planting proportion of food crops gradually increases and develops outwards with the cities as the center. The proportion of food crops increases from $50.06 \%$ in the city outskirts to $79.82 \%$ in typical rural areas. By contrast, the planting proportion of commercial crops gradually reduces, and reduces from $49.94 \%$ in the city outskirts to $20.18 \%$ in rural areas.

\subsubsection{The Planting Structure of Farmers in the Non-protection Areas}

We can find from the data in Table 1, the major planting subject of farmers in non-protection areas is commercial crops and the planting area of food crops is small. Since farmers in non-protection areas are not constrained by the policy of basic farmland protection, they necessarily choose the commercial crops with relatively high profits as the planting subject.

Table 1. The planting structure of crops in non-protection areas

\begin{tabular}{llll}
\hline Types of crop & & Area & Percentage \\
\hline Food crops & Corn & Unit (Mu) & $1.62 \%$ \\
& Fiber crop & 2 & $9.71 \%$ \\
Commercial crops & Fruits and vegetable & 12 & $85.84 \%$ \\
& Forests & 106.1 & $2.83 \%$ \\
Total & & 3.5 & \\
\hline
\end{tabular}

3.1.3 Comparison of the Planting Structure of Farmers in Protection Areas and in Non-protection Areas

Through the statistics on 189 effective questionnaires among farmers, we get the statistical result as shown in Table 2. The planting structures in the basic farmland protection areas and in the non-basic farmland protection areas are different. The planting structure in the protection areas is mainly food crops, which is also mixed with other kinds of commercial crops. The planting structure in the non-protection areas is mainly commercial crops, including all kinds of fresh vegetables and other commercial crops of flowers and fruits, etc.

Table 2. Comparison of the structure of planting crops in different areas

\begin{tabular}{llll}
\hline & Planting area & Protection areas & Non-protection areas \\
& Unit: $\mathrm{Mu}$ & Unit: $\mathrm{Mu}$ & Unit: $\mathrm{Mu}$ \\
\hline Food crops & 771.3 & 769.3 & 2 \\
Commercial crops & 646.35 & 524.75 & 121.6 \\
Total & 1417.65 & 1294.05 & 123.6 \\
\hline
\end{tabular}

From the above table, we can see that obvious discrepancy exists between the protection areas and non-protection areas in terms of their preference for planting food crops and commercial crops. The planting rate of food crops by farmers in the protection areas is $59.45 \%$ and the planting rate of commercial crops is $40.55 \%$. By contrast, the planting rate of food crops by farmers in non-protection areas is merely $1.62 \%$ and the planting rate of commercial crops is as high as $98.38 \%$. Thus, it can be seen that the protection policy for basic farmland has large constraint impacts on farmers in the protection areas, which leads to great discrepancy between the planting structures of farmers in both the two areas. It is obvious that commercial crops have higher profits than food crops. Hence, since farmers in the protection areas are much constrained in terms of cultivation, they have no other choice but to cultivate food crops to a larger extent, which causes lower profits of farmers in the protection areas compared with farmers in the non-protection areas. 


\subsection{Imbalance of Interests Reflected by the Income Structure}

\subsubsection{The Situation of Income of Farmers in the Protection Areas}

It is discovered through a statistical analysis of field survey, different crop planting structures lead to obvious discrepancy of net agricultural income among farmers from different types of rural areas. The annual net agricultural income of each peasant household in the protection areas is 8522.51 RMB Yuan. It is the 67 peasant households in the city outskirts that have the highest annual agricultural income of 9569.03 RMB Yuan, and the annual net agricultural income of 9067.23 RMB Yuan among the 66 peasant households in typical rural areas is the second and the 33 peasant households in the outer suburban district have the lowest annual net agricultural income of 4986.89 RMB Yuan, which is far lower than the average level.

\subsubsection{The Situation of Income of Farmers in the Non-protection Areas}

It is calculated that the net agricultural income of each peasant household in the non-basic farmland protection areas is 17427.08 RMB Yuan according to the survey data. The following figure is the income structure of the peasant households in non-basic farmland protection areas. It can be seen that, the agricultural income of farmers in non-protection areas accounts for a high proportion of the total income. It is possible for farmers who are not classified into to basic farmland protection areas may select more with more freedom the agricultural crops they would like to cultivate so as to obtain relatively more economic profits. However, constrained by production, the ultimate result of farmers in the protection areas is that the agricultural income accounts for a small proportion of the total income of the family.

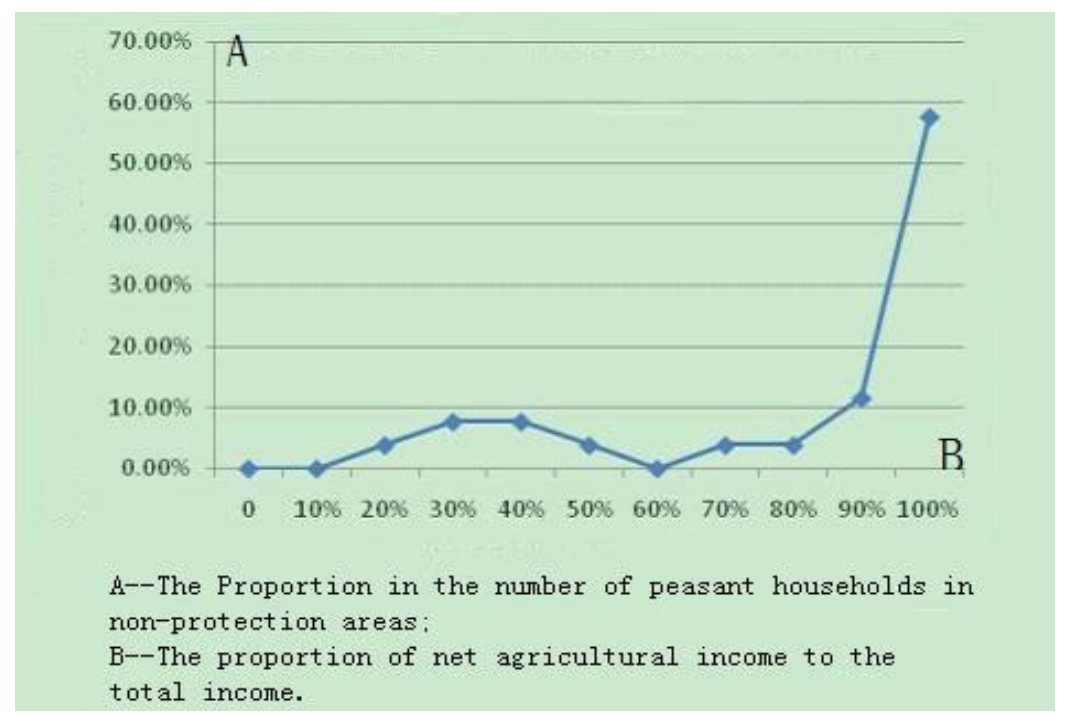

Figure 1. The income structure of peasant households in non-protection areas

\subsubsection{The Situation of Income of Urban Citizens}

It is calculated that the monthly average income of urban citizens is 4441.2 RMB Yuan according to the survey data, and accordingly, their annual average income is 53294 RMB Yuan.

\subsubsection{Comparison of the Situation of Income of Residents in All Areas}

It can be known from the above data that, if cultivated land is classified as a basic farmland protection area, then the variety of crops cultivated will be constrained and farmers will have to burden high opportunity costs for protecting their cultivated land. That is to say, farmers will lose the opportunities to cultivate commercial crops that have high profits or to go outside to the cities to search for a job, which will lead to reduced net agricultural income of farmers. According to the above statistical data, the annual net agricultural income of farmers in non-protection areas is twice the annual net income of farmers in the protection areas. As a result, farmers in the protection areas have to switch to seek for other forms of economic income under the temptation of high profits. For instance, they may choose to cultivate those kinds of commercial crops that have higher profits but large destructive effects in the basic farmland or they may directly leave their land uncultivated to go outside to the cities to search for a job. The phenomenon of outward employment among farmers in the typical rural areas is especially common. In the process of the field survey, we have had a specific understanding in that and the agricultural income of a lot of peasant households only accounts for a proportion of $1 \%-30 \%$ of the total income of the family. However, in non-protection areas, the economic benefits farmers obtain in cultivating land has 
been able to satisfy their demands for the normal life, so the agricultural income in more than $50 \%$ of households in the non-protection areas accounts for almost $100 \%$ of the total family income.

From Table 3, we can see that the benefit per Mu of land cultivated by farmers in the protection areas is quite low, so farmers in the protection areas who cultivate food crops have relatively high opportunity costs. The formula of opportunity cost of farmers in the protection areas is as below:

The opportunity cost of farmers in basic farmland protection areas in cultivating basic farmland

$=$ the benefit per $\mathrm{Mu}$ of land in non-protection areas (Yuan/Mu)

$=$ The total benefit of the protection areas/the cultivation area of the non-protection areas (Yuan/Mu) (Formula 1)

Table 3. Statistical table of profits of different crops in different areas

\begin{tabular}{lllll}
\hline & \multicolumn{2}{c}{ Total profits } & \multicolumn{2}{l}{ Average profits per Mu } \\
\hline & Protection areas & Non-protection areas & Protection areas & Non-protection areas \\
Food crops & 370209.1917 & 2660 & 481.2286 & 1330 \\
Fiber crops & 102132.105 & 11200 & 869.9498 & 933.3333 \\
Oil crops & 53294.39565 & 0 & 399.9579 & 0 \\
Fruits and vegetable & 352150.9082 & 413656 & 948.6824 & 3898.737 \\
Forest & 90087.75 & 0 & 10009.75 & \\
Crude drugs & & 38500 & & 11000 \\
\hline
\end{tabular}

When we substitute the value in Table 3 into the above formula, we finally calculate that the opportunity cost loss per $\mathrm{Mu}$ of land of farmers in the protection areas is 3770.36 Yuan. It can be discovered from the above data that, when the cultivated land is classified as basic farmland, the opportunity cost of each Mu of land is 3770.36 Yuan. On the other hand, compared with farmers who go outside to cities for employment, farmers who cultivate land in the protection areas also have corresponding opportunity costs. Assuming that a farmer who goes outside to the cities for employment works for eight hours each day and 300 days each year and his salary is 7 Yuan each hour, then his opportunity cost is 16800 Yuan.

According to the survey data, the overall benefit per Mu of cultivated land in the protection areas is as following: Benefit per $\mathrm{Mu}$ of cultivated land in the protection area $=$ the total benefits of the protection area/cultivation land of the protection area. When we substitute this survey data into the formula, we can calculate that the benefit per $\mathrm{Mu}$ of cultivated land in the protection area is 877.8 Yuan. The ratio of the benefit per Mu of cultivated land in the protection area to the benefit per $\mathrm{Mu}$ of cultivated land in the non-protection area is 1:4.3. However, the ratio of the annual income of farmers in the protection areas to the annual income of urban citizens is 1:6.25.

\section{The Approach of Resolving the Issue of Interest Imbalance among Farmers in Basic Farmland Protection Areas}

As the subject of formulating the protection policy, the government should carry out relevant improvement policies with regards to this issue as soon as possible and mobilize the enthusiasm of farmers in protection by mans of formulating some economic compensation policies. At present, the land resource protection job is still quite austere. Thus, we should absolutely not loosen our alert. Instead, we should continue to adhere to improvement of the former policies and carry out new policies so as to better resolve the issue of protection of cultivated land.

There are mainly the following several specific countermeasures.

\subsection{To Mobilize Farmers' Enthusiasm in Basic Farmland Protection by Means of Carrying Out a Series of Economic Compensation Policies}

Economic compensation mechanism is the core for sustainable development of protection of cultivated land, whereas the operation mechanism is an important means for effective operation of the economic compensation mechanism and balance of interests is the basic principle in establishing the operation mechanism (Yuan Guang $\&$ Ren Decheng, 2009). Whether a policy is successful or not lies in whether it will not cause new problems at the time of resolving corresponding problems. The new problem caused by the protection policy of the basic farmland is that it leads to unfair re-distribution of income and this unfairness, in turn, will affect the effect of the protection policy. Thus, in order to resolve this problem, it is quite necessary to give economic compensation to farmers in a rational way. 


\subsection{To Institutionalize and Rationalize Basic Farmland Protection by Means of Strict Legal Constraint}

Expedited progress of urbanization leads to the prominent contradiction that construction site occupies cultivated land. Although the country has promulgated a series of policies to ban this by explicit order, unreasonable land acquisition still occurs frequently under temptation of enormous profits. Yet, legalization of protection of cultivated land is able to make protection of cultivated land obtain powerful support, which helps to realize long effectiveness of protection. However, simultaneously, it is necessary to take all into consideration in carrying out laws and regulations, so as to guarantee justice in implementation of the laws and regulations and avoid re-occurrence of the same problems existing in the former policies.

\subsection{To Re-evaluate the Value of Cultivated Land}

Value of cultivated land not only contains the agricultural crop value of the cultivated land. The US Environmental Economist A.M. Freeman believes that, as a result of externality, property of public goods and existence of other factors, quite a lot of services provided by the resource-environment system fail to be effectively adjusted by the market. On one hand, re-evaluation of the value of cultivated land is helpful for protection of cultivated land and avoids its flow in a random way. On the other hand, in the process of flow of agricultural land, considering the new value of the cultivated land, interests of farmers in the protection areas might be effectively guaranteed. Re-measurement of the value of the "products" enables the market mechanism to play its role out of freedom.

With development of economy, the country has gradually begun to concentrate on the situation of all fields in the economic life. In order to maintain social stability, it is necessary for the country to pay attention to the issue of "Three Rural" so as to pour persistent motive power into development of the country. The essence of the issuer of "Three Rural" is the issue of rational utilization of land resources. This receives much concentration and rational development and utilization of land resources will be more close to the reality. Thus, the country will necessarily gradually pay attention to the disadvantages existing in the protection policy of basic farmland and resolve these problems. Of course, the prospect of relevant issues is optimistic.

\section{References}

A. Myrick Freeman. (2002). The Measurement of Environmental and Resource Values--Theory and Method. Beijing: China Renmin University Press Co.

Chen, Baiming. (2004). Situation and Counter Measures for Protection of Arable Land and Basic Farm Lands. Journal of China Agricultural Resources and Regional Planning, 10(5).

Chen, Meiqiu, Deng, Aizhen, Zhou, Bingjuan, Liu, Zhongting, Wu, Ping, \& He, Weijia. (2005). An Empirical Study on Farmers' Feelings among Different Groups on Cultivated Land Protection. China Soft Science, (9), 16-22.

Han, Longda, \& Liu, Jinsong. (2009). Causes for Low Efficiency of China's Basic Farmland Protection Policy and Countermeasures Under Planned Control. Scientific and Technological Management of Land and Resources, (4), 112-115.

Jiang, Guanghui, Kong, Xiangbin, Zhang, Fengrong, Li, Cuizhen, \& Zheng, Hongbin. (2009). Analyzing the Mechanism of Economic Compensation for Farmland Protection. China Land Science, 7(7).

Nie, Qinghua, \& Bao, Haosheng. (1999). A Review and Preview of Prime Farmland Protection in P. R. China. China Population, Resources and Environment, 9(4), 31-35.

Nie, Qinghua, \& Bao, Haosheng. (1999). Experience and Enlightenment of Farmland Resources Protection in Foreign Countries. Economic Geography, 4(2).

Tang, Jian. (2004). Problems and Countermeasures in Basic Farmland Protection. China Land, 7.

Yang, Xiaoguang, \& Jiang, Haoran. (2008). Study on Development of Basic Farmland Protection Zones Surrounding Big Cities. Lanzhou Academic Journal, 4.

Yuan, Guang, \& Ren, Decheng. (2009). The Construction of Compensation Operating Mechanism for Cultivated Land Protection from the Perspective of Balanced Interests. Journal of Shandong University of Sciences \& Technology (Social Science), 10(5). 